\title{
A IMPORTÂNCIA E A FORMAC̣ÃO DO PROFESSOR-LEITOR
}

\author{
Cynthia de Fátima Sousa Oliveira Moura ${ }^{1}$ \\ Antônia Aparecida Lima Lopes ${ }^{2}$
}

RESUMO: Neste trabalho propomos identificar a importância do professor-leitor para o atual cenário educacional brasileiro. Para tanto, foi feito um estudo de fundamentação teórica e, especialmente, de revisão literária com a busca de publicações que indicassem aspectos essenciais sobre a importância do professor-leitor e as estratégias de formação continuada para motivar a leitura entre os docentes. Logo, foram selecionadas obras diversas sobre o assunto, tais como livros, artigos e outros materiais de publicação científica ou publicitária, as quais deram suporte para a análise teórica do tema em estudo. Algumas das principais referências utilizadas para esta pesquisa foram: Bandeira (1999), Zilberman (2008), Quadros e Miranda (2009), Alves (2013), Amorim e Farago (2015), Lima e Alves Neto (2015) e Ribeiro e Moura (2015). Com a construção do texto, percebeu-se que a discussão sobre a importância do professor-leitor se faz muito necessária à prática escolar, uma vez que os docentes têm responsabilidades para motivar a leitura entre seus alunos, principalmente aqueles que lecionam na educação infantil e anos iniciais do ensino fundamental, quando a criança está reconhecendo mundo da leitura que existe ao seu redor.

PALAVRAS-CHAVE: Formação. Professor-leitor. Leitura. Docência.

\section{INTRODUÇÃO}

Atualmente, os educadores são unânimes em afirmar que a prática de leitura é importante às pessoas de todas as idades, especialmente durante a escolarização, o que leva a acreditar que o professor deve ser um incentivador da leitura. Assim, reconhece-se que a prática de leitura é de fundamental importância em todos os níveis e modalidades de escolaridade, tendo sua iniciação já na educação infantil.

Logo, é essencial que o professor da educação infantil (bem como aquele que leciona nos anos iniciais do ensino fundamental) seja também um praticante da leitura - apesar de não ser esta a realidade destes docentes (AMORIM e FARAGO, 2015). Apesar da grande importância da influência docente na leitura dos estudantes, pressupõe-se que, pelas mais diversas razões, a prática da leitura não seja frequente entre os professores da educação básica. Cabe a estes profissionais e às escolas em que trabalham repensar a prática da leitura, pois sugere-se que um professor que não lê não contribuirá para o desenvolvimento do seu aluno.

Diante disso, este trabalho tem como objeto de estudo a formação do professor-leitor, considerando sua atuação como docente na educação básica, tendo como foco central o exercício da docência na educação infantil e nos anos iniciais do ensino fundamental. Com base

1 Instituição: Centro Universitário UNIMETA, E-mail: cynthiafsom@ig.com.br

2 Instituição: Centro Universitário UNIMETA, Orcid: https://orcid.org/0000-0002-3689-6043, E-mail: ant.gestao@gmail.com 
neste objeto, o objetivo geral da pesquisa será identificar a importância do professor-leitor para o atual cenário educacional brasileiro.

Assim, este objetivo geral pode ser desmembrado em outros dois objetivos específicos: apresentar a essencialidade do professor-leitor para o incentivo à leitura entre seus estudantes; identificar estratégias para a formação continuada do professor-leitor. Para tanto, os dois itens que serão descritos na fundamentação teórica deste texto seguirão o direcionamento dado por estes objetivos específicos.

Há muitos trabalhos voltados para o incentivo da leitura entre os estudantes, sendo eles crianças, adolescentes e adultos. Entretanto, há poucas publicações que enfatizam os professores - que estão em sala de aula e/ou os que ainda estão em formação - como leitores reais que incentivem a leitura entre seus alunos. Se a leitura é uma prática tão importante - mas, igualmente, infrequente - não se pode negar que os professores devem apreciar este hábito (QUADROS e MIRANDA, 2009).

Segundo os estudos de Souza et al. (2005), o docente também precisa ser estimulado à leitura para, então, incentivá-la entre os discentes, sendo essa uma das grandes razões que motivaram o presente estudo. Perceber aspectos que ajudem a compreender como consolidar a profissionalidade do professor-leitor, desde a educação infantil, fez com que surgisse o interesse em se pesquisar sobre o assunto. Acredita-se que é essencial que a criança, ao iniciar sua vida escolar, já seja despertada para a leitura - por alguém que acredita nesta prática. Imagina-se que um professor-leitor reconhece que, somente quem gosta de ler, saberá a importância que é formar leitores (ALVES, 2013).

Assim, o incentivo à leitura aos docentes deve receber um especial estímulo nos cursos de formação de professores, uma vez que um professor, envolvido com a prática de leituras, incentivará o hábito de ler entre seus alunos (QUADROS e MIRANDA, 2009).

Com o intuito de conhecer como os cursos de formação de professores trabalham, bem em como conhecer os professores que incentivam "novos" e "antigos" leitores, deu-se origem à construção deste trabalho. Para tanto, foi feito um estudo de fundamentação teórica e, especialmente, de revisão de literatura com a busca de publicações que indicassem aspectos importantes sobre a prática do professor-leitor e de estratégias de formação continuada promovidas para este profissional. Logo, foram selecionadas leituras sobre o assunto com consulta feita em livros, artigos e outros materiais de publicação científica ou publicitária, as quais deram suporte para a análise teórica do tema em estudo.

Segundo Gil (1991), os exemplos mais característicos desse tipo de pesquisa são aqueles que se referem às investigações sobre ideologias ou aqueles que se propõem à análise das diversas posições acerca de um problema. Já Lüdke e André (1986) acreditam que, para realizar uma pesquisa, é preciso promover um confronto entre os dados, as evidências, as informações coletadas sobre determinado assunto e o conhecimento teórico acumulado a respeito dele. Isso se trata, portanto, de construir uma porção do saber. Deste modo, esse conhecimento não é só fruto da curiosidade, da inquietação, da inteligência e da atividade investigativa do pesquisador, mas também da continuação do que foi elaborado e sistematizado pelos que já trabalharam o tema anteriormente.

Assim sendo, a pesquisa realizada será apresentada, neste texto, da seguinte forma: após esta introdução, será exibido o primeiro momento da revisão literária que traz elementos im- 
portantes à compreensão da importância do professor-leitor. Em seguida, serão apresentados trabalhos que retratam estratégias de formação continuada para a consolidação do professor-leitor. Por fim, serão indicadas as considerações finais, consolidando a discussão final que tem por intuito destacar os pontos principais da figura do professor-leitor na formação dos estudantes.

\section{DESENVOLVIMENTO}

A seguir são apresentados os dois itens centrais de revisão deste trabalho. O primeiro item trata da importância do professor-leitor para que ele seja, de fato, um docente interessado pela prática de leitura e que, por conseguinte, estimule a leitura entre seus alunos.

Já o segundo item aborda estratégias práticas que estimulem o hábito de leitura entre os professores, que já estão em serviço na educação infantil e anos iniciais do ensino fundamental. Assim, será possível reconhecer ações simples e consolidadas que motivem professores a se deleitar pela leitura.

\section{A IMPORTÂNCIA DO PROFESSOR-LEITOR PARA O INCENTIVO À LEITURA ENTRE SEUS ESTUDANTES}

Para que seja possível a compreensão dos aspectos relacionados à formação do professor-leitor, é fundamental o entendimento das denominações indicadas como formação e professor-leitor.

Alguns dos significados da palavra formação, em uma definição dicionarizada ${ }^{3}$, é a similaridade com "modo de criação", "educação", "instrução". Outra interpretação interessante, embora oposta à do dicionário, é a apresentada por Alves (2016, p. 14) ao indicar que "Formatura": 'formar' é colocar na forma, fechar. Um ser humano 'formado' é um ser humano fechado, emburricado. Educar é abrir. Educar é 'desformar'”. Logo, quando a abordagem tem por intuito descrever a formação do professor-leitor, o que vem à mente é aquele profissional voltado para as práticas de leituras e comprometido em contagiar positivamente seus alunos com essa prática, por pressupor a importância (e o deleite) em se tornar um bom leitor. Além disso, um professor que pratica a leitura, continuamente, reconhece que esta prática delimita sentidos, já que enquanto lemos ou escrevemos, interpretamos e compreendemos (ORLANDI, 2006).

Já o termo professor-leitor sugere a figura do docente que mantém o hábito e o gosto pela leitura. Assim, abordar a formação leitora do professor, é partir da hipótese de que se o professor não é leitor, ele não é capaz de formar leitores. Para tanto, ressalta-se aqui a importância deste profissional para estimular "a leitura não como o resultado satisfatório do processo de letramento e decodificação de matéria escrita, mas como atividade propiciadora de experiência única com o texto literário" (ZILBERMAN, 2008, p. 17).

Dando um enfoque ainda maior ao docente, que atua na primeira infância, os estudos de Amorim e Farago (2015) apontam que a educação infantil é o período no qual a leitura se torna ainda mais necessária, pois, para que a criança adquira e se envolva com esta importante prática, é fundamental que ela seja estimulada a ler desde cedo. Entretanto, para que tal estímulo aconteça, é essencial que o professor seja um adepto da leitura e, portanto, a incentive entre seus alunos.

3 Dicionário online da língua portuguesa. Disponível em: https://www.dicio.com.br/formacao/ Acesso em: 30 mai. 2020. 
O professor tem papel fundamental no ensino da leitura, sendo o mediador das diversas práticas de leitura que ocorrem dentro da sala de aula, utilizando de diferentes recursos para realizar uma atividade significativa para a criança (AMORIM e FARAGO, 2015, p. 147).

Nesse sentido, é fundamental que o professor consiga ler além do que as palavras dizem simplesmente. Como bem coloca Souza (1992), a leitura é o ato de perceber e atribuir significados através de uma conjunção de fatores pessoais com o momento, o lugar e as circunstâncias. Assim, ler é interpretar uma percepção sob as influências de um determinado contexto, o que leva o leitor a um processo de compreensão particular da realidade. Coerente a essa visão, Gonçalves (2013, p. 10) apresenta a importância da iniciação à leitura desde o início da escolarização.

[...] se torna indispensável que desde os anos iniciais escolares, textos, frases, palavras, sílabas e letras, tudo isso tenha um sentido para a criança, pois é a partir deste processo que ela poderá criar o hábito pela leitura de forma estimulante e fascinadora. Que o professor seja, antes de tudo, um leitor.

Dessa forma, se a criança em seus anos escolares iniciais tiver um professor-leitor, que seja envolvido com as práticas de leitura, irá saber conduzir seus alunos para o maravilhoso mundo do saber através de diversas leituras. Sabendo que a criança tende a imitar o seu professor, o docente precisa conduzir o despertar da leitura entre seus alunos, estimulando-os ao contar histórias, demonstrar interesse por gêneros textuais diversos e oferecer livros coerentes com a escolaridade das crianças. Para tanto, é preciso que o professor seja um leitor convicto; do contrário, esta será uma tarefa árdua e pouco coerente com a docência, como bem coloca Rocco (1999, p. 120).

O professor que não lê nunca terá a memória povoada pelas ricas e inesquecíveis imagens fornecidas pelas diferentes formas dos textos de arte, principalmente pelos textos literários. Se assim for, se o professor não se revelar um leitor, ele jamais conseguirá trabalhar com leitura;

Entretanto, é justamente o panorama do desinteresse pela leitura que tem povoado a rotina de muitos docentes. Vários professores não vivenciam uma agradável experiência com a leitura e suas dificuldades com a prática e o estímulo deste hábito entre seus alunos se acentuam; afinal, estes não são professores que se tornam exemplos para a motivação à leitura entre seus estudantes (QUADROS e MIRANDA, 2009).

Em contrapartida, ainda existem professores que motivam seus alunos a ler. Segundo a pesquisa intitulada "Retratos da Leitura no Brasil", publicada pelo Instituto Pró-Livro (2011), o professor é um dos principais influenciadores da leitura. É importante ressaltar que esta pesquisa contou com uma amostragem de 5.012 entrevistas domiciliares em 315 municípios de todos os estados e o Distrito Federal, como pode ser visto na imagem abaixo. 
Figura 1 - Principais influenciadores para a prática de leitura

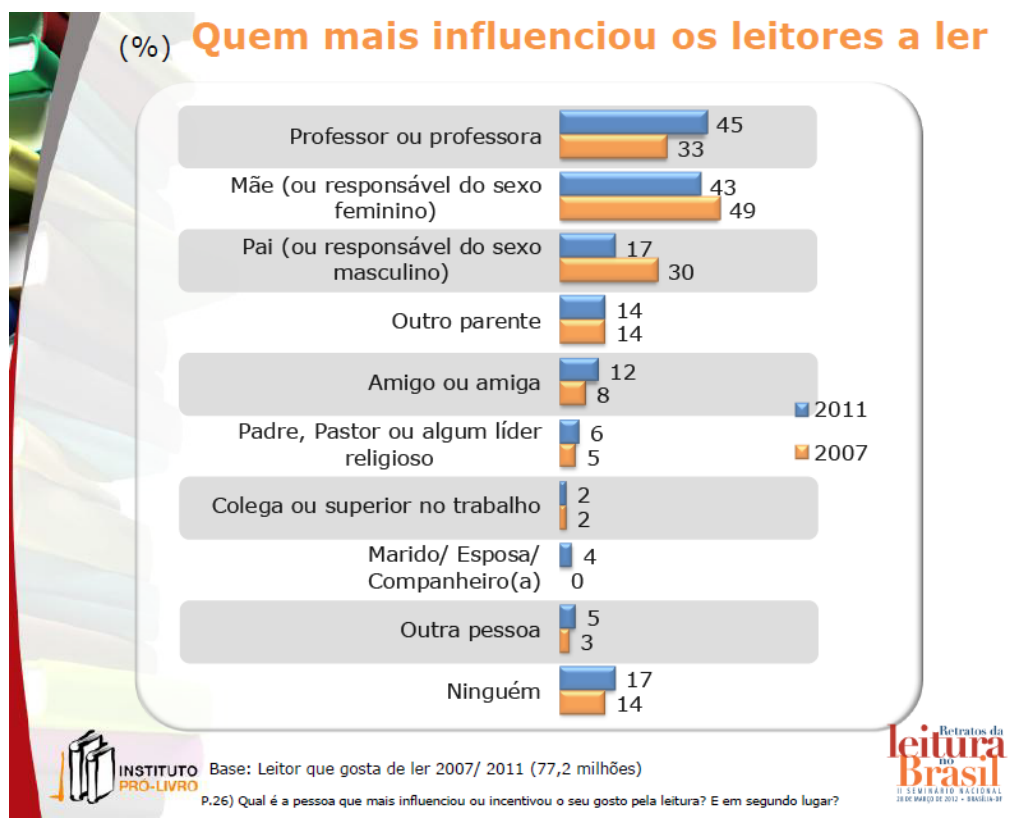

Fonte: Instituto Pró-Livro (2011)

Esta mesma pesquisa mostra que, dentre os entrevistados, $51 \%$ não tem lido, no último ano, mais livros do que costuma ler; deste percentual, 20\% afirma ler menos do que já leu no passado. Estes entrevistados atribuem razões diversas para justificarem a diminuição no hábito da leitura, como pode ser visto na figura a seguir.

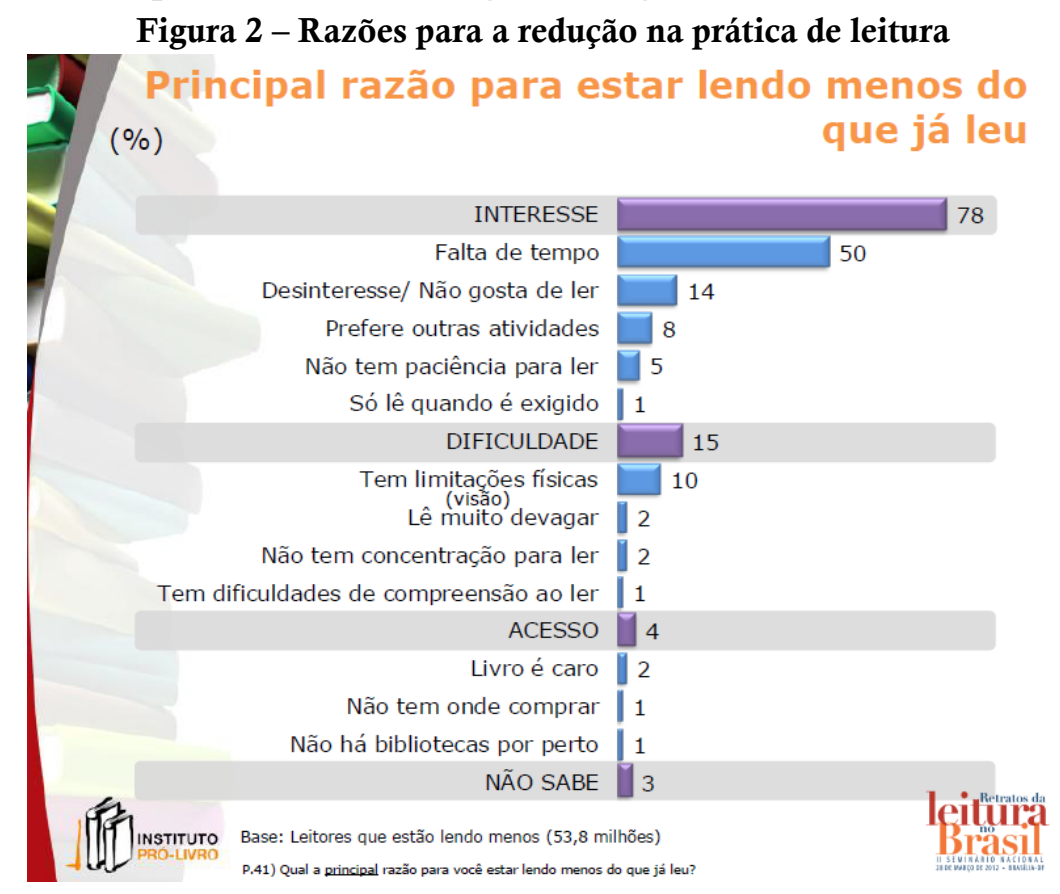

Fonte: Instituto Pró-Livro (2011)

Polato (2012), ao entrevistar a organizadora da referida pesquisa, Zoara Failla, indicou que, de todos os professores participantes da pesquisa (145 sujeitos), apenas três disseram que gostam de ler no tempo livre. Ao serem questionados sobre títulos preferidos, eles citaram os de autoajuda e religiosos. 
Novamente, se confirma a ideia de que professores que não sentem o deleite da leitura não podem contagiar seus alunos com este prazer; "imaginar que quem não lê pode fazer ler é tão absurdo quanto pensar que alguém que não sabe nadar pode se converter em instrutor de natação" (MACHADO, 2001, p.122).

Há a consciência de que ser professor requer muito estudo, aprimoramentos e práticas que viabilizem o alcance de competências pedagógicas para exercer diversos conhecimentos em sala de aula (LIMA e ALVES NETO, 2015). Logo, a escola tem grande responsabilidade em oportunizar, para seus professores, momentos e situações que os incentivem a se manterem atualizados ou que adquiram a busca pelo sempre tão almejado conhecimento, alcançados através da leitura. É sobre esta questão que o próximo item tratará a seguir.

\section{ESTRATÉGIAS DE FORMAC̣ÃO CONTINUADA PARA O PROFESSOR-LEITOR}

Acredita-se que um professor-leitor poderá formar um aluno-leitor que, consequentemente, terá mais chances de se tornar um cidadão-leitor com mais conhecimentos em um mundo mais letrado (FERREIRA e SANTOS, 2010).

Como bem coloca Rangel (2012), o professor é o mediador por excelência, entre os suportes de leitura e os leitores, sendo a sua atuação essencial na formação do leitor. Se o professor tem uma boa base literária, por conhecer seus alunos, ele terá maior possibilidade de saber reconhecer que tipo de leitura poderá fazer para conquistar cada aluno seu para o maravilhoso universo da leitura. Para isso, esse professor deveria ser conhecedor de diversos tipos de leituras - especialmente aquelas que o encantam para o ato de ler.

Para tanto, é essencial que a escola institua meios para que os professores, que não mantêm o hábito da leitura, passem a fortalecê-lo ou, até mesmo, a criá-lo - de preferência em momentos de formação continuada. Em uma visão coerente, Souza et al. (2005, p. 218) defendem que

\footnotetext{
Entende-se que, ainda que todos os quesitos ideais necessários a uma prática de ensino da leitura fossem efetivados na escola, indispensável seria a presença de professores leitores, que sentissem prazer na leitura, que fossem bem informados e instrumentalizados para tal prática. O ensino da leitura e, particularmente, a importância da literatura na formação pessoal e intelectual do ser humano, encontram pouco espaço nos programas de formação inicial e continuada (SOUZA et al., 2005, p. 218)
}

Nesse sentido, é fundamental ressaltar o que se considera como formação continuada. De acordo com Silva (2000), a formação continuada é uma atividade sequencial, que acontece durante a carreira do docente, em momentos que a escola pode oferecer situações de aperfeiçoamento ou em cursos para o aprimoramento do trabalho já realizado pelo docente. Segundo Pimentel (2004), esse tipo de formação se fortaleceu nos últimos anos diante das inúmeras lacunas deixadas pela formação inicial para o exercício docente.

São os momentos de formação continuada que podem se tornar situações, promovidas pela escola, para que seus professores passem a conviver com o prazer da leitura. Porém, ainda há poucos relatos nesse sentido, já que "existem ações diversas que propõem a motivação à leitura entre os alunos do ensino fundamental; entretanto, poucos trabalhos sugerem ações direcionadas para o estímulo ao hábito de ler entre os professores" (RIBEIRO e MOURA, 2015, p. 10). 
Uma das principais ações que podem ser praticadas é a organização de diálogos em que estes profissionais possam se reunir para falarem de leitura, em um momento que seja voltado para isso. Para tanto, a estratégia para incentivar a leitura entre professores é idêntica para quando se quer formar alunos leitores: é preciso oferecer livros (CHARÃO, 2014).

Charão (2014) - ao citar a obra de Zilberman (2008) - aponta que nas políticas de distribuição de livros escolares transparece a necessidade de um pequeno investimento para aquisição destas obras. A grande demanda que persiste é a criação de estratégias que abram espaço, nas rotinas escolares, para que os professores tenham oportunidade de expressar suas dificuldades com a leitura e expor suas necessidades. Diante disso, a autora relata uma experiência exitosa: uma roda de empréstimo e apreciação. Nesta, os professores levam um livro que foi importante para eles e o apresentam aos demais, o que estimula outros professores a lerem - bem como facilita o problema da aquisição de obras.

Outra alternativa é apresentada por Medeiros (1999), que sugere encontros, motivadores à leitura entre os professores, em lugar agradável, fora da sala de aula, tais como o pátio, um local embaixo de uma árvore, no refeitório ou qualquer outro lugar que esteja longe dos ritos pedagógicos. É fundamental que sejam estabelecidos encontros sistemáticos com uma rotina prazerosa, oferecendo um tempo no qual a leitura seja compartilhada e, assim, se possa refletir, discutir, comentar, dar e trocar opinião, bem como descobrir e reverter talentos desconhecidos por falta de oportunidade. Sobre a periodicidade, a autora indica:

Que esses encontros aconteçam de quinze em quinze dias, uma vez por mês, aos sábados, no horário complementar. Não importa. O importante é que sejam sistemáticos, que estabeleçam uma rotina prazerosa e não se tornem um evento, um tapa-buraco nas reuniões pedagógicas ou um espaço de reflexão no início de qualquer atividade (MEDEIROS, 1999, p. 55-56).

Medeiros também aponta que essas propostas de leitura podem oferecer o real conhecimento entre os participantes, quase sempre estranhos, apesar do convívio de longos anos. Logo, é preciso que eles se identifiquem e se emocionem com as leituras partilhadas com os colegas.

\section{CONSIDERAÇÕES FINAIS}

O presente texto teve, como objetivo geral, identificar a importância do professor-leitor para o atual cenário educacional brasileiro. Tal objetivo fora cumprido e ficou explícita a necessidade de que o docente não seja apenas o profissional que leciona, mas também o professor-leitor que os estudantes precisam para, então, tornarem-se cidadãos leitores.

As leituras realizadas sugerem também que, sem um professor verdadeiramente leitor, o estudante terá pouca (ou nenhuma) chance de se tornar um aluno-leitor. Entretanto, as pesquisas mais recentes apresentam professores desinteressados pela leitura - o que pode justificar algumas razões que levam a maioria dos brasileiros a não se interessarem pelo hábito de ler.

Percebeu-se também que há estratégias simples e eficientes que podem levar o professor, que não mantém o hábito de ler, a querer se deixar seduzir pela leitura. É nesse sentido que a formação continuada se faz necessária para a consolidação de professores-leitores. 
Entretanto, a necessidade da formação continuada, para "criar" o professor-leitor, deixa explícita a carência deste pressuposto na formação inicial. Oliveira (2008) aborda a má formação dos professores de língua portuguesa, desde a educação básica, bem como a jornada exaustiva a que são impostos, sem grandes opções para recusar longas horas de trabalho. Nesse panorama, é possível pensar que "se o professor não teve meios de se tornar sujeito de suas escolhas, será difícil que se torne o sujeito de suas leituras" (OLIVEIRA, 2008, p. 177).

Portanto, é fundamental repensar a formação docente desde a educação básica pública e, especificamente licenciaturas e Pedagogia, oferecer disciplinas voltadas para a prática de leitura na docência. Formar um professor, sem que ele tenha a mínima valorização pelo ato de ler, é correr o risco em se gerar um profissional sem compromisso com seu alunado e sem interesse em se ter um mundo mais digno de conhecimentos - características indispensáveis à docência.

Na verdade, o que há de mais importante na formação (e "continuidade") do professor leitor é justamente o sentimento trazido por Bandeira (1999, p. 152-153):

\begin{abstract}
Precisamos de multidões de bons professores, capazes de seduzir nossas crianças para a leitura. Falei em seduzir? Pois é isso. Como diz o educador francês Daniel Pennac, o verbo ler é parente dos verbos sonhar e amar, pois nenhum dos três suporta o imperativo. Ninguém pode ordenar que uma pessoa ame ou sonhe; ela sonha ou ama se quiser. $\mathrm{O}$ mesmo acontece com a leitura. Precisamos de professores que não forcem seus alunos a ler, mas de profissionais sedutores que demonstrem o prazer, $\mathrm{o}$ tesão que é ler uma boa história.
\end{abstract}

Estes profissionais "sedutores" só poderão existir se forem despertados para este encantamento.

Por isso, falar sobre a importância do professor leitor, quando muitos falam sobre a importância em se formar leitores em geral, é uma espécie de "alerta". Há muitos docentes com a responsabilidade em motivar seus alunos à leitura, principalmente aqueles que lecionam na educação infantil e anos iniciais do ensino fundamental; momento no qual a criança está reconhecendo mundo da leitura que existe ao seu redor.

Assim, reconhece-se a grande responsabilidade tanto entre os docentes e seus alunos quanto entre os próprios docentes. Se o professor-leitor conseguir despertar também seu colega, que não tem tanto apreço pela leitura a se interessar por ela, estará construindo ao seu redor uma rede de leitores com tendência a se propagar pela escola, nas famílias dos seus alunos, na sua comunidade. São incalculáveis as maravilhas que pode fazer um professor-leitor e, assim, formar leitores e melhorar a visão de mundo de tantas pessoas.

Imagine se, então, nos cursos de formação de professores houvesse uma disciplina voltada ao incentivo da leitura, dedicada aos futuros profissionais da educação. O curso de Pedagogia, especialmente, teria a oportunidade de oferecer profissionais capazes de despertar (e consolidar) a leitura entre tantos cidadãos.

Admite-se que, se o docente também precisa ser estimulado à leitura, uma vez que ele é o principal incentivador dos seus alunos, é preciso que os cursos de formação de professores invistam mais em seus futuros profissionais. Espera-se que as escolas contribuam mais no apoio aos seus professores para florescerem neles esse hábito. Que os professores, em especial 
os que lecionam na educação infantil e anos iniciais do ensino fundamental, estimulem seus alunos para que, assim, descubram o mundo mágico da leitura nos primeiros anos escolares.

\section{THE IMPORTANCE AND THE FORMATION OF THE READER TEACHER}

ABSTRACT: In this work we propose to identify the importance of the reading-teacher for the current Brazilian educational scenario. To this end, a study was carried out with theoretical foundation and, mainly, a literary review with the search for publications that pointed out essential aspects about the importance of the reading-teacher and the strategies of continuing education to motivate reading among teachers. For this purpose, several works on the theme were selected, such as books, articles and other materials for scientific or advertising publication, which provided subsidies for the theoretical analysis of the subject under study. Some of the main references used for this research were: Bandeira (1999), Zilberman (2008), Quadros and Miranda (2009), Alves (2013), Amorim and Farago (2015), Lima and Alves Neto (2015) and Ribeiro e Moura (2015). With the construction of the text, it was realized that the discussion about the importance of the reading-teacher is very necessary for school practice, since teachers have the responsibility to motivate reading among their students, especially those who teach in early childhood education, when the child is recognizing the world of reading that exists around him/her.

KEYWORD: Formation. Reading-teacher. Childhood education.

\section{REFERÊNCIAS}

ALVES, R. 300 pílulas de sabedoria. São Paulo: Planeta, 2016, p. 14

ALVES, R. Ostra feliz não faz pérola. São Paulo: Planeta, 2008.

AMORIM, M.C.B.; FARAGO, A.C. As práticas de leitura na educação infantil. Cadernos de Educação: Ensino e Sociedade, Bebedouro, n.2, v.1, p.134-154, 2015. Disponível em: http:/ /unifafibe. com.br/revistasonline/arquivos/cadernodeeducacao/sumario/35/06042015200353.pdf Acesso em: 30 mai. 2020.

BANDEIRA, P. Capítulo 23 - Pedro Bandeira. In: PRADO, J.; CONDINI, P. A formação do leitor: pontos de vista. Rio de Janeiro: Argus, 1999. Disponível em: https://filosoficabiblioteca.files. wordpress.com/2013/11/prado-condini-a-formac3a7c3a3o-do-leitor-pontos-de-vista.pdf Acesso em: 30 maio. 2020.

CHARÃO, C. Formação do professor leitor é o primeiro desafio de políticas de incentivo à leitura nas escolas. Abre livros [online]. 2014. Disponível em: http://www.abrelivros.org.br/home/index.php/ noticias/5744-formacao-do-professor-leitor-e-o-primeiro-desafio-de-politicas-de-incentivo-a-leituranas-escolas. Acesso em: 30 mai. 2020.

FERREIRA, S.P.A.; SANTOS, E.M. Constituição do professor-leitor: condições e compreensão de leitura em alunos universitários. Psicol. teor. prat., São Paulo, v.12, n.2, p.96-111, fev. 2010. Disponível em: http://pepsic.bvsalud.org/pdf/ptp/v12n2/v12n2a07.pdf. Acesso em: 30 mai. 2020. GATTI, Bernadette Angelina (Org.) et. al. Por uma revolução no campo da formação de professores. São Paulo: Editora Unesp, 2015.

GERALDI, J. W. A aula como acontecimento. São Carlos: Pedro \& João Editores, 2010.

GIL, A.C. Métodos e técnicas de pesquisa social. 3. ed. São Paulo: Atlas, 1991.

GONÇALVES, D.S.N. A importância da leitura nos anos iniciais escolares. Monografia-Licenciatura em Pedagogia. Universidade do Estado do Rio de Janeiro. São Gonçalo, 2013. Disponível em: http:// www.ffp.uerj.br/arquivos/dedu/monografias/dsng.pdf. Acesso em: Acesso em: 30 mai. 2020.

GUERREIRO, C. O novo formador. Revista Educação [online]. 2012. Disponível em: http://www. revistaeducacao.com.br/?s=\%22professor+leitor\%22. Acesso em: 30 mai. 2019.

INSTITUTO PRÓ-LIVRO. Retratos da Leitura no Brasil. 2011. Disponível em: http://prolivro.org. br/home/images/relatorios_boletins/3_ed_pesquisa_retratos_leitura_IPL.pdf. Acesso em: 30 mai. 2020.

LIMA, S.S.L.; ALVES NETO, F.R. Desafios na prática pedagógica do docente iniciante em Instituições 
de Ensino Superior. Revista Saberes da Fameta. Rio Branco, v.2, n.1, 2015. Disponível em: https:// unimeta.edu.br/wp-content/uploads/sites/12/2018/03/3.pdf. Acesso em: 30 maio. 2020.

LÜDKE, M.; ANDRÉ, M.E.D.A. Pesquisa em educação: abordagens qualitativas. São Paulo: EPU, 1986.

MACHADO, A.M. Ponto de fuga: conversas sobre livros. São Paulo. Companhia das Letras, 2001.

MARIN, Alda Junqueira (Org.). Educação Continuada: reflexões, alternativas. Campinas, SP: Papirus, 2000.

MARTINS, Heloisa Helena T. de Souza. Metodologia qualitativa de pesquisa. IN: Educação e Pesquisa, São Paulo, v.30, n.2, p. 289-300, maio/ago. 2004.

MEDEIROS, E.L.D. Capítulo 8 - Elza Lucia Dufrayer de Medeiros In: PRADO, J.; CONDINI, P. A formação do leitor: pontos de vista. Rio de Janeiro: Argus, 1999. Disponível em: https:// filosoficabiblioteca.files. wordpress.com/2013/11/prado-condini-a-formac3a7c3a3o-do-leitorpontos-de-vista.pdf. Acesso em: 30 mai. 2020.

OLIVEIRA, G.R. O professor de português e a literatura: relações entre formação, hábitos de leitura e prática de ensino. Universidade de São Paulo - Mestrado em Educação. São Paulo, 2008. Disponível em: https://teses.usp.br/teses/disponiveis/48/48134/tde-07102008-101148/pt-br.php. Acesso em: 30 mai. 2020.

ORLANDI, E.P. Discurso e leitura. 7. ed. São Paulo: Cortez, 2006.

PIMENTEL, A. Jogo e desenvolvimento profissional: análise de uma proposta de formação continuada de professores. Tese (Doutorado em Educacão) - Faculdade de Educação, Universidade de São Paulo, São Paulo, 2004.

POLATO, A. Zoara Failla: Se o professor não é leitor, não consegue transmitir o prazer pela leitura. Fórum Nacional pela Democratização da Comunicação (FNDC) [online], 2012. Disponível em: http://www.fndc.org.br/clipping/zoara-failla-se-o-professor-nao-e-leitor-nao-consegue-transmitir-oprazer-pela-leitura-27287/. Acesso em: 30 mai. 2020.

QUADROS, A. L.; MIRANDA, L. C. A Leitura dos Estudantes do Curso de Licenciatura em Química. Química Nova na Escola, São Paulo, v. 31, n. 4, p. 235-240, nov. 2009. Disponível em: http://qnesc.sbq.org.br/. Acesso em: 30 mai. 2020.

RANGEL, J.N.M. Leitura na escola: espaço para gostar de ler. Porto Alegre: Mediação, $3^{\mathrm{a}}$ ed., 2012. RIBEIRO, L.M.L.R., MOURA, C.F.S.O. "Sorteio de livros": a influência do fácil acesso a obras literárias na melhoria da formação de educadores. Revista Saberes da Fameta. Rio Branco, v.2, n.1, 2015. Disponível em: https://unimeta.edu.br/por-que-a-fameta/revista-saberes/edicao-2/. Acesso em: 07 set. 2019.

ROCCO, M.T.F. Capítulo 20 - Maria Thereza Fraga Rocco. In: PRADO, J.; CONDINI, P. A formação do leitor: pontos de vista. Rio de Janeiro: Argus, 1999. Disponível em: https://bibliotecadafilo.files. wordpress.com. Acesso em: 30 mai. 2020.

SILVA, A. M. C. A formação contínua de professores: uma reflexão sobre as práticas e as práticas de reflexão em formação. Educação e Sociedade, Campinas, n.72, p. 89-109, ago. 2000.

SOUZA, R.J. Narrativas Infantis: a literatura que as crianças gostam. Bauru: USC, 1992.

SOUZA, R.J., SOUSA, A.C., CASTRO, P.C.V., SOUZA, G.C. Leitura do Professor, Leitura do Aluno: processos de Formação Continuada. Unesp, 2005. Disponível em: file:///C:/Users/Usuario/ Downloads/leituraprofessor\%20(5).pdf Acesso em: 21 ago. 2019.

ZILBERMAN, R. O papel da literatura na escola. Via Atlântica, n. 14, p. 11-22, dez. 2008.

Data submissão: 30/05/2020

Data aprovação:20/06/2020 